\title{
Experimental models of Alzheimer's disease for deciphering the pathogenesis and therapeutic screening (Review)
}

\author{
XUEYUAN LI, XINJIE BAO and RENZHI WANG \\ Department of Neurosurgery, Peking Union Medical College Hospital, Chinese Academy of Medical Sciences and \\ Peking Union Medical College, Dongdan, Dong Cheng, Beijing 100005, P.R. China
}

Received April 26, 2015; Accepted December 2, 2015

DOI: $10.3892 / \mathrm{ijmm} .2015 .2428$

\begin{abstract}
Despite decades of laboratory and clinical research, Alzheimer's disease (AD) is still the leading cause of dementia in adults and there are no curative therapies currently available for this disease. This may be due to the pathological features of $\mathrm{AD}$, which include extensive extracellular amyloid plaques and intracellular neurofibrillary tangles, as well as subsequent neuronal and synaptic loss, which begin to appear several years prior to memory loss and the damge is already irreversible and extensive at the time of clinical diagnosis. The poor therapeutic effects of current treatments necessitate the introduction of experimental models able to replicate AD pathology, particularly in the pre-symptomatic stage, and then to explore preventive and therapeutic strategies. In response to this necessity, various experimental models reproducing human AD pathology have been developed, which are also useful tools for therapeutic screening. Although none of these models fully reproduce the key features of human $\mathrm{AD}$, the experimental models do provide important insight into the pathological changes which occur in AD. This review summarizes the commonly used experimental models of AD and also discusses how the models may be used to decipher the pathogenesis underlying AD and to screen novel therapies for this disease.
\end{abstract}

\section{Contents}

1. Introduction

2. Pathogenesis of AD

3. Transgenic animal models of AD

4. Non-transgenic animal models of AD

5. In vitro models of $\mathrm{AD}$

Correspondence to: Professor Renzhi Wang, Department of Neurosurgery, Peking Union Medical College Hospital, Chinese Academy of Medical Sciences and Peking Union Medical College, Dongdan, Dong Cheng, Beijing 100005, P.R. China

E-mail: wangrenzhipumch@163.com

Key words: Alzheimer's disease, models, natural, transgenic, in vitro
6. Current status and future development of experimental models of AD

7. Conclusion

\section{Introduction}

Alzheimer's disease (AD), also known as the most common form of dementia, is a progressive, neurodegenerative disorder in adults, afflicting 35.6 million individuals worldwide (1). Although a variety of therapies have been developed over the years to treat patients with $\mathrm{AD}$, none of these treatments are able to provide a cure, but merely alleviate the AD-associated symptoms. After recognizing the contributing role of synaptic loss in memory deficits, researchers have attributed the poor therapeutic effects in patients with AD to the pathological features of this disease. These features include extensive extracellular deposits of $\beta$-amyloid $(\mathrm{A} \beta$ ) plaques, intracellular neurofibrillary tangles (NFTs), as well as subsequent neuronal and synaptic loss, which often begin several years prior to memory loss and the damage is alread irreversible at the time of diagnosis.

In order to explore more effective treatments, a more complete understanding of the pathophysiology of AD is required. As the pathological changes associated with $\mathrm{AD}$ are initiated several years prior to the onset of clinical signs $(2,3)$, it is impossible to probe the human neuropathology at this stage. However, on the positive side, animal models are valuable tools which may be used to simulate the pathological changes associated with human AD and then to decipher the pathogenesis, particularly in the pre-symptomatic stage. In particular, the advent of transgenic animal models, in combination with non-transgenic animals, has allowed researchers to conduct in-depth studies of AD $(4,5)$. Animal models cam reproduce the overt changes occurring in patients with AD; however, complex in vivo conditions may limit the accessibility to the tissue of interest and prevent real-time and spatial measurements of biological changes (6). Consequently, several in vitro experimental models of $\mathrm{AD}(7,8)$, which provide detailed regional and cell-level information, have been developed to enhance the usefulness of in vivo animal models. All these models are of value for deciphering the fundamental mechanisms underlying AD pathology and also, for the testing of novel therapies targeted against this disease. 
However, the currently available experimental animal models are not without drawbacks, and none of these models replicate all the features of $\mathrm{AD}$. In addition, it is necessary to take into account the extent to which the results obtained from the experimental models may be applicable to humans, as well as consideration of how to use these models to the best of their potential. In this review, we summarize the experimental models of $\mathrm{AD}$ that are currently in use, focusing on the similarities and differences to human disease presented by each of these models, for the purpose of generating more useful information on how to use these models when testing novel therapeutics. Furthermore, we hope to provide the basis for developing more appropriate models for AD research.

\section{Pathogenesis of AD}

In pathological terms, the $\mathrm{AD}$-affected brain is characterized by widespread senile plaques of extracellular $\mathrm{A} \beta$ peptides, intracellular NFTs, as well as neuronal and synaptic loss (Fig. 1). Senile plaque is composed of a central core formed by Congo red-positive $A \beta$ proteins and degenerating nerve endings surrounding the $A \beta$ core. NFTs are neuronal inclusions of the microtubule-associated protein (MAP) tau and consist of aggregated, hyperphosphorylated tau. In AD pathology, senile plaques and NFTs appear in the hippocampus, the entorhinal and polymodal association cortices, and the basal forebrain. These brain regions are also severely affected by neuronal and synaptic loss. In addition to the neuropathological changes, there are also a number of pathophysiological disturbances occurring in the $\mathrm{AD}$-affected brain, including inflammatory reactions, such as angiogenesis and gliogenesis (9).

Nowadays, it is recognized that the loss of synapses mostly correlates with the cognitive deficits and dementia associated with $\operatorname{AD}(10,11)$. With respect to the causes of synaptic loss, there are several hypotheses although a general consensus exists in favor of the 'amyloid cascade hypothesis': $\mathrm{A} \beta$, particularly highly fibrillogenic $A \beta$ developed following the hydrolysis of amyloid precursor protein (APP), initiates a neurotoxic cascade, consequently causing neurodegeneration and ultimately, AD (Fig. 1). APP, an ubiquitously expressed transmembrane protein, is involved in the regulation of neuronal proliferation, migration and differentiation under normal conditions. In AD, overexpressed APP is hydrolyzed by $\beta$-secretase and then $\gamma$-secretase into $A \beta$ peptides. $A \beta$ peptides are toxic to neurons and induce neuronal and synaptic damage when assembled into amyloid fibrils (Fig. 1). It has also been reported that acetylcholinesterase (AChE), an enzyme responsible for the hydrolysis of the neurotransmitter acetylcholine (ACh), may promote $A \beta$ assembly (12) and form stable complexes with $A \beta$ fibrils (13). The A $\beta / \mathrm{AChE}$ complex has proven to be more toxic to cultured neurons than $A \beta$ fibrils alone (14). This may explain why cholinergic neurons are the major cell types destroyed in patients with AD. In addition, presenilin (PS)1 and PS2, as well as apolipoprotein $\mathrm{E}$ (ApoE) bind to soluble $\mathrm{A} \beta$ in vitro, and promote the formation of $A \beta$ fibrils in an isoform-specific manner. $A \beta$ fibrils can also induce tau hyperphosphorylation by activating several protein kinases, including glycogen synthase kinase-3 $\beta$ (GSK-3 $\beta$ ), MAP kinase and microtubule affinityregulating kinase (15). Hyperphosphorylated tau, combined with unassembled microtubules, accumulates to form NFTs in neurons and dendrites, leading to neuronal degeneration and ultimately, AD (Fig. 1).

The tendency of familial aggregation and early-onset of $\mathrm{AD}$ in patients has urged researchers to investigate the genetic etiology of this disease. Currently, it has been recognized that some forms of AD are caused by the inheritance of mutant genes, including genes encoding APP (16), PS1 (17) and PS2 (18), tau (19) ApoE (20) and $\beta$ - and $\gamma$-secretase (21). It has also been reported that individuals harboring $\alpha$-macroglobulin (22) and endothelial nitric oxide synthase-3 mutant genes (23) are more susceptible to $\mathrm{AD}$ than others.

\section{Transgenic animal models of AD}

Since the discovery of AD-associated genes, a number of transgenic animal models have been generated by introducing mutant genes into the existing genetic makeup or modifying genes of interest using gene targeting technology so as to model some features of human AD (5) (Table I). Mice are the most commonly used species for transgenic modeling due to their easy manipulation and accessibility. Transgenic models have also been created in rats, although thye are not so widely available (24). Different transgenic animal models are discussed in more detail below.

APP transgenic mice. The first, widely used transgenic mouse models of $\mathrm{AD}$ were developed to express the transgene of human APP (Table I). In earlier studies $(25,26)$, transgenic mice harboring APP mutations merely exhibited an accumulation of intracellular $A \beta$ and occasional behavior deficits, but no senile plaques, suggesting that cognitive impairment occur independently of plaque formation, but correlate with $A \beta$ fibril formation. The lack of senile plaques in these models was supposed be associated with the low expression levels of the APP gene. In subsequent studies, a mutant human APP gene controlled by platelet-derived growth factor- $\beta$ promoter (PDAPP) was used as a transgene in mice, which produced extensive extracellular A $\beta$ deposits, synaptic loss and astrocytosis, with plaque formation at 6-9 months of age (27). Consistent with these observations, other transgenic models, including Tg2576 and APP23 (both carrying a Swedish double mutation, $\mathrm{APP}_{\mathrm{Swe}}$ ), demonstrated APP overexpression in addition to neuronal loss in the CA1 region, and learning deficits as was observed in the PDAPP transgenic mice (28). Moreover, $\operatorname{Tg} 2576$ mice developed $A \beta$ plaques at 8 months of age, with a 5-fold increase in the concentrations of $A \beta 40$ and a 14-fold increase in those of $\mathrm{A} \beta 42$ (28), whereas plaque formation occurred in APP23 mice at 6 months of age, together with a notable decrease in the CA1 pyramidal neurons which correlated inversely with the plaque loads in this region (29). When a human mutant presenilin gene was introduced, $T g \mathrm{APP}_{\text {Swe }}$ mice displayed abundant plaques in the neocortex, olfactory bulb, thalamus and hypothalamus at an earlier age (30). These mice also exhibited progressive plaque accumulation, astrocytic and microglial activation, as well as behavioral deficits related to A $\beta 42$ loads in the hippocampus.

These findings provide support for the 'amyloid cascade hypothesis' as an explanation for the pathogenesis of $\mathrm{AD}$, and the experimental models provide valuable tools for the testing of A $\beta$-modifying drugs. However, APP transgenic mice seldom present with NFTs and neuronal loss, which are the hallmarks 


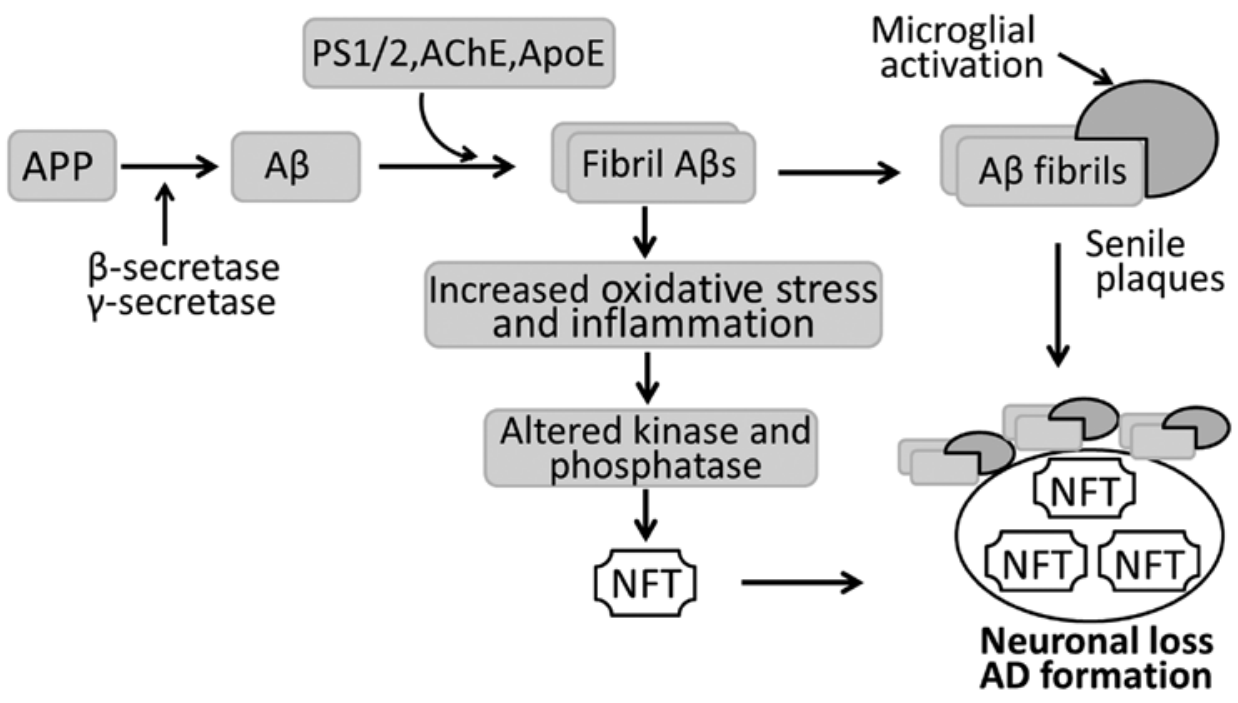

Figure 1. Schematic diagram of the pathogenesis of Alzheimer's disease (AD). In AD, amyloid precursor protein (APP) is hydrolyzed by $\beta$-secretase and then $\gamma$-secretase into $\beta$-amyloid (A $\beta$ ) that aggregates to form fibril A $\beta$ s. Fibril A $\beta$ s cause neuronal and synaptic loss, and extensive fibrils, along with activated microglia, accumulate to develop senile plaques. Fibril A $\beta$ s can also induce neurofibrillary tangles (NFTs) by activing various kinase and phosphatases, with neuronal loss and AD as a result. AChE, acetylcholinesterase; ApoE, apolipoprotein E; PS, presenilin.

of AD. This may be associated with the fact that multiple genes, rather than APP alone, are involved in the occurrence of AD and information learned from studies of familial AD (fAD) may not be applicable to sporadic AD (sAD) (31).

Tau transgenic mice. In order to elucidate the role of tau in the pathology of $\mathrm{AD}$, transgenic mouse models have been developed to express human tau protein using different promoters. As there are 6 tau isoforms in humans, numerous transgenic models have been created. In a previous study, when a human gene encoding a 4-repeat form of tau (P301L) under the PrP promoter was expressed in mice, the tau levels were significantly increased in the neurons of the somatosensory cortex and the motor neurons of the spinal cord (32). The majority of these mice, however, exhibited motor deficits or hind limb paralysis and exhibited no NFT-like changes (33), which was inconsistent with the changes observed in humans. Thus, this model doses not induce a phenotype representing human AD (34). In another study, extensive NFTs were also observed in a new mouse model (Thy-Tau22) that expresses 4-repeat human tau mutated at two sites of G272V and P301S under a Thy1.2 promoter, and synaptic dysfunction and synapse loss were also evident (10). Behavioral analysis of the diseased mice revealed progressive anxiety, delayed learning, as well as spatial memory without motor deficits. In this mouse model, neuropathologies occurred at 3 months of age, and NFTs were formed mainly in the hippocampus (10). Of particular note, neuronal loss in the P301L tau mice was lower than that in the P301S tau mice, echoing the fact that patients with early onset of fAD carry the P301S mutation (35).

Glial tau inclusions are commonly observed in patients with fAD. This can be modeled in mice using P301L and widetype human tau which are driven by 2',3'-cyclic nucleotide 3'-phosphodiesterase and glial fibrillary acidic protein (GFAP) promoters, respectively $(36,37)$ (Table I). These two mouse models exhibit neuronal dysfunction and axonal degeneration, suggesting that tau pathology affects neurons.
Taken together, tau transgenic models have proven that mutations in the tau gene can accelerate tau aggregation and cause nerve-cell dysfunction or loss in vivo, thereby imitating an important aspect of human fAD. These models provide valuable tools for AD research with respect to the role and mechanism of tau hyperphosphorylation and aggregation in regulating $\mathrm{AD}$ pathology.

APP and tau double transgenic mice. As mentioned above, A $\beta$ deposits and NFTs are two features of AD pathology; however, the interaction between $A \beta$ deposits and NFTs remains to be elucidated (31). APP and tau double transgenic mice are candidate models containing both pathological features of AD, which can be used to investigate the interaction between $A \beta$ and tau (Table I). By crossing APP Tg2576 transgenic mice with VLW lines expressing human mutant tau, transgenic mice carrying both APP and tau genes were obtained (32). These double transgenic mice demonstrated a 7-fold increase in NFT formation accompanied by enhanced $\mathrm{A} \beta$ deposits in the olfactory bulb and amygdala compared with that observed in the tau transgenic mice alone; however, no significant difference in the tau level was observed between the single and double transgenic mice $(32,38)$. These results suggest that the A $\beta$ deposits promote NFT formation in AD in double transgenic mice and then enhance the neuropathological correlates of AD brain. This is consistent with the results of other studies demonstrating that Thy1.2 promoter-driven P301L mice injected with A $\beta 42$ exhibited a 5-fold increase in NFT formation at 18 days after the injection of $A \beta$ into the amygdala (39). Taken together, these findings challenge the idea that tauopathy is merely a downstream effect of $A \beta$ deposition, and confirm that $A \beta$ deposits interact with tau protein in vivo, and indicate that the interaction between $A \beta$ and tau should be further studied as a potential target for AD therapies.

Triple transgenic mice. Despite plaque and NFT formation, the APP and tau double transgenic mice exhibited the same level 
Table I. Summary of transgenic animal models of AD mentioned in this review.

\begin{tabular}{|c|c|c|c|c|}
\hline Models & Transgene & Pathological changes & Neurological deficits & Refs. \\
\hline \multicolumn{5}{|c|}{ APP transgenic mice } \\
\hline PDAPP & $\begin{array}{l}\text { hAPP695(Ind), } \\
\text { PDGF promoter }\end{array}$ & $\begin{array}{l}\text { A } \beta s ; \text { plaques at } 6-9 \text { months; } \\
\text { synaptic loss; astrocytosis; no NFTs }\end{array}$ & Cognitive deficits at 6 months & $(27)$ \\
\hline APP23 & $\begin{array}{l}\text { hAPP751(Swe), } \\
\text { Thy-1 promoter }\end{array}$ & $\begin{array}{l}\text { Plaques at } 6 \text { months; vascular A } \beta \text { deposits; } \\
\text { synaptic loss; inflammation; no NFTs }\end{array}$ & Cognitive deficits at 3 months & (29) \\
\hline $\operatorname{Tg} 2576$ & $\begin{array}{l}\text { hAPP } 695(\text { Swe }) \\
\text { HamPrP promoter }\end{array}$ & $\begin{array}{l}\text { Extensive plaques in cortical and limbic } \\
\text { structures at } 8 \text { months; synaptic loss; no NFTs }\end{array}$ & \multicolumn{2}{|c|}{ Cognitive impairment at 9 months (28) } \\
\hline PS2APP & $\begin{array}{l}\text { hAPP695(Swe), } \\
\text { PSEN2(N141I), }\end{array}$ & $\begin{array}{l}\text { Severe plaques at } 5 \text { months; synaptic loss, } \\
\text { inflammation; glial activation; no NFTs }\end{array}$ & $\begin{array}{l}\text { Behavioral and cognitive } \\
\text { decline at } 8 \text { months }\end{array}$ & $(30)$ \\
\hline
\end{tabular}

Tau transgenic mice

$\begin{array}{cl}\text { PrP-Tau } & \text { hTau(P301L), } \\ & \text { MurinePrP promoter } \\ \text { Thy-Tau22 } & \text { hTau(P301S), } \\ & \text { Thy-1.2 promoter } \\ \text { GFAP-Tau } & \text { hTau(P301L), } \\ & \text { GFAP promoter }\end{array}$

APP and tau double transgenic mice

$\begin{aligned} \text { APP/tau } & \text { hAPP695(Swe), } \\ & \text { hTau(P301L); } \\ & \text { PrP promoter }\end{aligned}$

Triple transgenic mice

$\begin{aligned} \text { 3xTg-AD } & \text { hAPP695(Swe) } \\ & \text { Thy1 promoter, } \\ & \text { hTau(P301L) } \\ & \text { Thy1 promoter, } \\ & \text { PSEN1(M146V)mPS1 } \\ & \text { promoter }\end{aligned}$

Five transgenic mice
Age- and gene-dependent development of NFTs in brain and spinal cord 6 months NFTs; mild astrogliosis; synaptic loss

Astrocytic tau pathology; mild BBB disruption; focal neuron damage

A $\beta$ deposits; NFTs; nerve loss at 8-15 months

$\mathrm{A} \beta$ deposits at 6 months; NFTs at 10-12 months; neuronal and synaptic loss; microglial activation; inflammation

Behavioral and motor deficits at 6 months

Decline in learning at 3 months, (10) memory at 6 months

Motor deficits

Motor disturbance

Age-related behavior deficits PSEN1(M146L, L28V); gliosis; synaptic loss; no NFTs

Thy 1 promoter

Transgenic rats for AD

$\begin{array}{llll}\text { APP }_{\text {Swe }} & \text { hAPP751(Swe), } & \text { Increased A } \beta 40 \text { and A } \beta 42 \text { peptide } & \text { Learning and memory } \\ \text { PS1APP } & \text { PDGF promoter } & \text { at 17-18 months; plaques } & \\ & \text { PAPP695(Swe), } & \text { A } \beta \text { deposits at 7 months; astrocytic } & \text { Behavioral deficits } \\ & \text { synapsin I promoter } & \text { and microglial activation; } & \\ \text { Thy-Tau } & \text { hTau truncated (151-391), } & \text { Increased p-tau reactivity; no NFTs } & \\ & \text { Thy1 promoter } & \text { tangles in cortex; no neuron loss } & \text { Decreased lifespan }\end{array}$

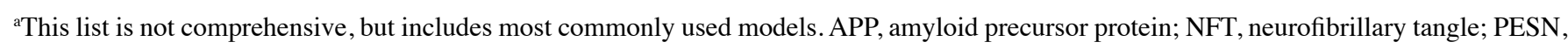
presenilin; p-tau, phosphorylated tau.

of $\mathrm{A} \beta$ deposits compared to that in the single APP transgenic mice, indicating that these mouse models do not accurately reflect $\mathrm{AD}$. Triple transgenic mice (3xTg-AD), expressing $\mathrm{APP}_{\mathrm{Swe}}, \mathrm{PS}_{\mathrm{M} 146 \mathrm{~V}}$ and tau $\mathrm{P}_{\mathrm{P} 01 \mathrm{~L}}$ transgenes, have been shown to develop extracellular $A \beta$ deposits from 6 months of age and a tau-related pathology at 10-12 months of age, which began in the hippocampus and then expanded to the neocortex, closely mimicking the development pattern of $\mathrm{A} \beta$ and tauopathy in the human AD brain (40) (Table I). At the same time, amyloidosis and tauopathy were accompanied by neuronal and synaptic loss, and age-related behavior deficits were also present prior to the development of plaques and tangle pathology (40). In this model, microglial activation and the upregulation of inflammatory markers were observed at 3 months of age, in parallel 
with the increase in $A \beta$ deposits (41). It appears that this model simulates the key pathological features of human AD and has the potential to be used to validate therapies targeting the mechanisms underlying AD pathology. This model has been widely used in the study of AD pathophysiology and the testing of potential therapies.

5xFAD transgenic mice. Although triple transgenic mice present a neuropathology similar to that observed in AD, most transgenic models develop plaques slowly (31). To accelerate plaque formation and the effects of very high cerebral $\mathrm{A} \beta$ levels, investigators generated new transgenic mice that co-expressed five fAD mutant genes (5xTg-AD) and $\mathrm{A} \beta$ plaque formation was increased at 2 months of age $(42,43)$. These $5 x T g-A D$ mice produced excessive amounts of $A \beta 42$, exceeding that of $A \beta 40$, suggesting that fAD mutations, when combined together, have an additive effect, resulting in increased $A \beta 42$ production and the promotion of plaque formation at an early age (43). This model exhibits an extensive accumulation of intraneuronal $A \beta 42$ within the neuronal soma and neurites at 1.5 months before plaque formation, indicating that intracellular $\mathrm{A} \beta$ deposits may be involved in plaque formation, neurodegeneration and neuronal loss (31). Furthermore, 5xTg-AD mice exhibited marked gliosis, reduced synaptic markers, and notable memory and cognitive loss. However, abnormal tau hyperphosphorylation was not observed in the 5xTg-AD mice $(42,43)$. These findings suggest that more complex mechanisms than the 'amyloid cascade hypothesis' alone are involved in the pathogenesis of AD and further analysis of pathological tau epitopes is required (31). The rapid development of amyloid pathology in the 5xTg-AD mice renders them candidate models for studying AD-like amyloidosis. However, the condition that this model represents rarely occurs since no cases of AD have been reported to carry all five familial mutations (31); this should be taken into account when using the data obtained from this model.

Transgenic rats. Transgenic rats offer distinctive advantages over mice in many aspects, including rich, well-characterized behaviors, as well as being closer genetically, physiologically and morphologically to humans than mice. Thus, great efforts have been made to develop models of AD in transgenic rats, as well as in transgenic mice (Table I). The earliest transgenic rat models of AD were developed by using wide-type APP transgene, which exhibited an accumulation of intracellular $A \beta$ without extracellular senile plaques (44) until 17-18 months of age $(45,46)$. When a human PS1 transgene was introduced, the resulting rats exhibited progressive plaque accumulation, astrocytic and microglial activation, tau hyperphosphorylation, as well as behavioral deficits related to $A \beta 42$ loads in the hippocampus, with the onset of $A \beta$ deposition at 7 months (45). The first transgenic rat models developing progressive NFTs expressed a human 3-repeat tau protein (47), which formed NFTs in neocortices at 9 months of age. Unfortunately, this model exhibited no neuronal damage in the hippocampus and neocortex, despite largest accumulations of tangles in these regions.

As a whole, the currently available transgenic rat models recapitulate some, but not all aspects of $\mathrm{AD}$, and thus, the extrapolation of obtained conclusions to humans requires a measure of caution. Furthermore, rat embryo cells are difficult to acquire due to technical reasons, and the survival of embryos after injection is low, thus rendering rat transgenesis more demanding and transgenic rats less accessible for AD research (4).

\section{Non-transgenic animal models of AD}

Natural AD models of $A D$. Memory loss is often the first, and common feature of old age. Thus, aged animals may potentially be used as natural models of memory deficits and dementia. Various animals ranging from rodents to non-human primates have been shown to spontaneously develop AD neuropathology followed by cognitive impairments similar to those observed in patients with AD $(21,48)$. These animals models are valuable tools that may be used to reveal the natural pathophysiology of $\mathrm{AD}$, since they are non-invasive and without any neurochemical manipulations (Table II).

The rodent is the most frequently used animal in experimental research due to the low cost, availability and ease of manipulation, as well as well-characterized behaviors (Table II). Prior studies conducted on rats have advanced our understanding of APP processing and revealed that neprilysin and insulin-degrading enzyme are the primary proteases implicated in $A \beta$ degradation $(49,50)$. Rats have also been used to investigate the spatial and temporal expression of different APP isoforms (51), the impact of $\mathrm{A} \beta$ aggregation on cholinergic and glutamine neurons (52), the influence of age or diet on the effects of intracerebral injections of $\mathrm{A} \beta$ peptides, correlations between cognitive deficits and AD pathology, as well as the cognitive improvements after new therapies. However, the primary structure and complete profile of $\mathrm{A} \beta$ peptide generated from APP processing in rats is different from that in humans (53), limiting their use in investigating the long-term effects of APP manipulation. Guinea pigs, another type of rodent, are similar to humans in terms of the A $\beta$ sequence and patterns of APP processing, making them suitable models for the study of the physiological functions of APP and A $\beta$ processing. Nonetheless, limitations still exist as to the use of this animal as there are no typical senile plaques and NFTs in the diseased brain and a lack of good behavioral assessments for this species (54).

Another example of a rodent model includes the senescence-accelerated mouse (SAM) model which simulates several of the silent features of AD (55). Early in 1981, SAM models were developed through phenotypic selection from a common genetic pool of $\mathrm{AKP} / \mathrm{J}$ strain of mice, including nine senescence-accelerated mouse-prone (SAMP) substrains that underwent accelerated aging and three senescence-accelerated mouse-resistant substrains that underwent normal aging processes (56). In subsequent studies, the SAMP8 strain was found to be a reliable model for dementia, developing deficits in memory and learning at an early age (57). OXYS rats have reportedly been used as senescence-accelerated models of AD-like pathology as their cognitive deficits are associated with the overexpression of APP, the accumulation of $A \beta$, as well as hyperphosphorylated tau in the brain (58). It has been demonstrated that senescence-accelerated rodents present with alterations in various genes and proteins that are involved in neuroprotection, signal transduction, oxygen species production (59) and immune reactions (60). Thus, these animals may be used to explore the underlying mechanisms behind agedependent learning and memory deficits at the gene and the protein level (21). 


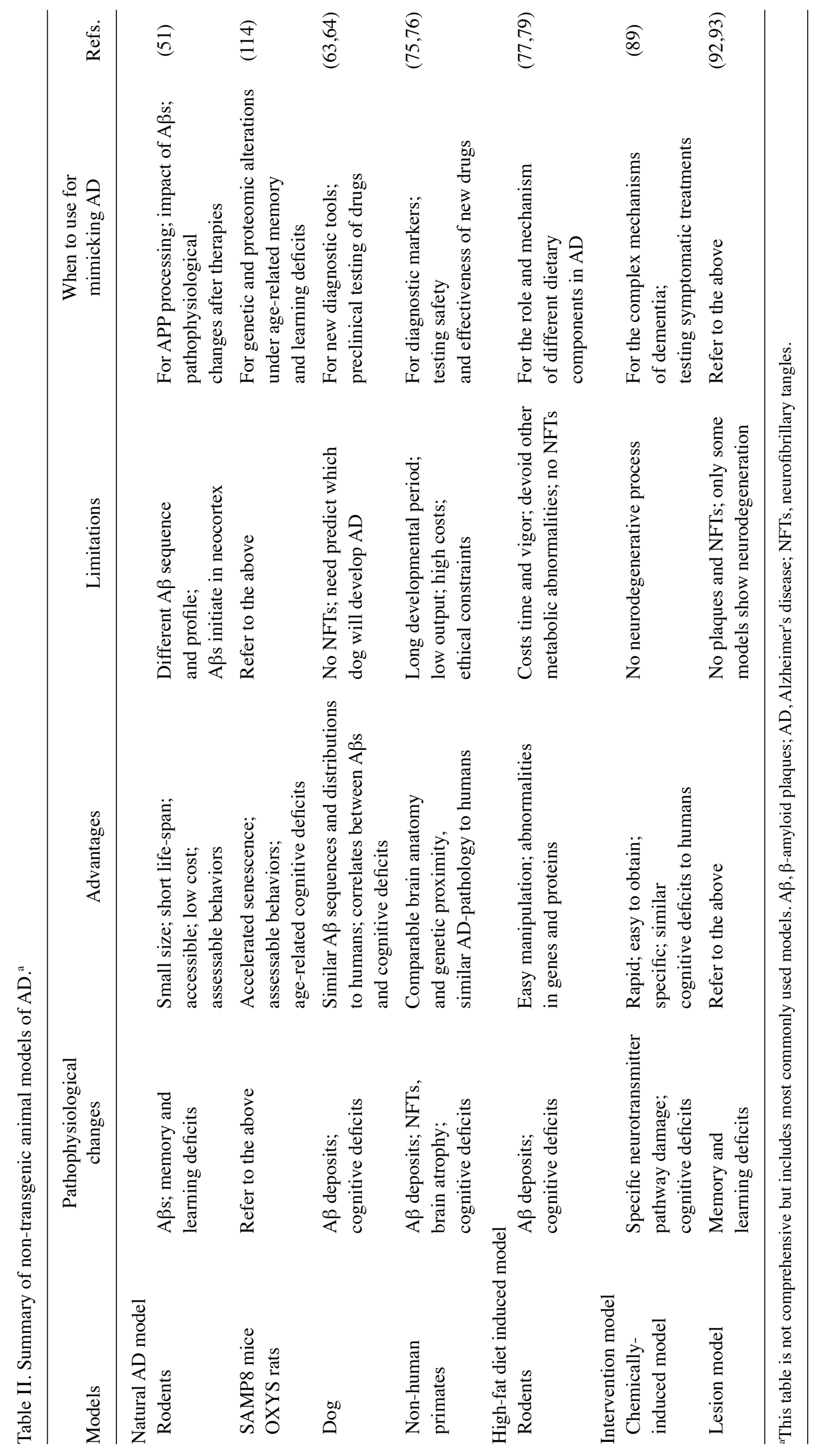


The dog has been proposed as a particularly suitable model for studying human $\mathrm{AD}$ due to the close phylogenetic proximity of canines to humans (61). Dogs have a conserved $A \beta$ sequence identical to humans and may spontaneously develop age-associated cognitive dysfunction resembling aspects of $\mathrm{AD}$, and measures of cognitive function have been well characterized. It has been reported that dogs develop diffuse $\mathrm{A} \beta$ deposits and age-associated plaques, and the extent of $\mathrm{A} \beta$ deposits correlates well with cognitive decline in the absence of NFTs $(62,63)$. In previous studies, histopathological analysis of a canine model of AD revealed that that the foremost and consistently impaired regions were within the prefrontal cortex, including the hippocampus and gyrus proteus $(63,64)$, and the anatomical spreading of $A \beta$ accumulation, beginning from the deep brain and progressing to the neocortex (64), in contrast to that observed in human AD. Due to the correlation between age-associated $\mathrm{A} \beta$ deposits and cognitive decline, dogs are the most widely used animals for the pre-clinical validation of a variety of drugs (66), and almost all therapies currently used for patients with $\mathrm{AD}$, including cholinesterase inhibitors, have been tested on dogs (67). However, NFTs and dense neuritic plaques do not appear consistently in all aging dogs, and $\mathrm{A} \beta$ accumulation is merely observed in a few dogs rather than appearing as a natural consequence of normal aging (68). In addition, some dogs develop heavy $A \beta$ burdens in their brains, but present with no apparent cognitive decline (69). Furthermore, the development of neuropathology takes a long period of time in dogs due to their relatively longer lifespan. This requires the exploitation of new diagnostic tools to predict which dog will develop AD-like symptoms. As such, dogs offer a useful model in the search for indicators for predicting AD.

Primates share many diseases of aging with humans and thereby are among the few animal species that develop agerelated neuropathologies similar to human $\mathrm{AD}$ (Table II). Of the primates, the mouse lemur serves as a reliable model that presents with $\mathrm{A} \beta$ plaques, NFTs and other AD-related pathologies (70), accounting for a more complete disease model. Moreover, this animal has a relatively short lifespan of 8-10 years, and approximately $20 \%$ of mouse lemurs aged 5 years or older have been found to exhibit notable cerebral atrophy, extensive $A \beta$ accumulation, tauopathy and cholinergic dysfunction (71). Further studies on mouse lemurs have revealed that brain atrophy is associated with $A \beta$ accumulation in parallel with cognitive impairment, and the age-related cytoskeletal abnormalities caused by NFTs are similar to those observed in humans (72). However, it should be noted that the $A \beta$ distribution in mouse lemurs differs from that in humans, in that $A \beta$ accumulation begings in the hippocampus of humans, but in the neocortices of mouse lemurs (73). In contrast to mouse lemurs, monkeys have a closer genetic proximity to humans and suffer significant AD-like lesions in the brain regions suspected to affect cognitive function when elderly (over 19 years of age) (74). These advantages make primates ideal models to identify diagnostic markers and to develop safe and effective treatments for human AD $(75,76)$. However, their long developmental period, low reproductive output, high costs and ethical constraints limit their wider application in studies of AD.

Models of high-fat diet (HFD)-induced AD. In these models, animals are fed a HFD, a process that results in hypercholester- emia (77) (Table II). Despite the presence of hypercholesteremia, these animals are not true models of $\mathrm{AD}$ as they are often devoid of other attendant metabolic abnormalities associated with $\mathrm{AD}$ (78). Dementia is always induced in HFD-fed rats over a 3-month period, with increased $A \beta$ deposits present at the same time (79). It has been shown that a HFD increases the brain cholesterol concentration by producing a higher serum cholesterol level, and there is a positive feed-back association between cerebral and serum cholesterol levels (80). As cholesterol plays an important role in the clearance and deposition of $A \beta$ peptide, increased cholesterol levels in the brain promote the generation and deposition of $\mathrm{A} \beta$ peptides (81), and $\mathrm{A} \beta$ deposits can cause cognitive decline by inducing inflammatory responses, as well as oxidative and nitrosative stress (82). During this process, insulin sensitivity and glucose intolerance are also decreased in HFD-fed animals, which increases the risk of susceptibility to AD (83). This model is often used to investigate the importance of different dietary components in AD pathophysiology. However, the experimental procedure involved with the use of this model is fat too time-consuming (84).

Intervention models of $A D$. The intervention model was established to explore the role of one specific neurotransmitter pathway in AD pathophysiology, and in particular to test the cholinergic hypothesis of AD (4). To establish such models, animals are subjected to intracranial injections of chemical substances or the induction of lesions into specific brain regions to reproduce AD (Table II). The established models represent some characteristics of $\mathrm{AD}$, such as deficits in cholinergic function and learning impairments (4).

The chemically-induced models of AD were established initially in rats (85) in order to investigate the effects of injected $A \beta$ on the surrounding neurons (52). Other substances used to induce an AD-like pathology include the relatively specific scopolamine for cholinergic neurons (86), L-methionine for activating NMDA receptors (87), okadaic acid for tau phosphorylation (88), sodium azide for mitochondrial dysfunction (89), as well as heavy metal for increasing reactive oxygen species (90). These substances induce dementia in animals by blocking neuronal or neurotransmitter pathways, which provide a distinctive means to study the effects of damage to a specific neurotransmitting pathway on cognitive function and also to test crucial drugs targeted at these pathways.

Lesion models were established based on previous findings showing that injury to specific brain regions, such as the medial temporal lobe produced memory loss (91). When a bilateral transection was performed in the hippocampal fimbria-fornix, memory and learning deficits were observed in the injured rats (92). In light of these findings, researchers imposed radiofrequency lesions to the lateral internal medullary lamina region of the thalamus in rats, which led to a significant cognitive decline in the diseased animals (93), and in addition, neurodegeneration similar to human $\mathrm{AD}$ was found in the brain regions of these rats distant to the site of injury (93). These lesion models offer novel insight into the multiple mechanisms of memory and learning loss, and are of particular use to develop symptomatic treatments for dementia.

As noted above, the intervention models replicate many of the clinical symptoms associated with $\mathrm{AD}$, suggesting complex mechanisms underlie memory and learning loss. Due to a lack 
Table III. Summary of identified aspects of AD by different in vitro models and the associated limitations.

\begin{tabular}{|c|c|c|c|c|}
\hline Models & Identified aspects of AD & Advantages & Limitations & Refs. \\
\hline \multicolumn{5}{|l|}{ Tissue models } \\
\hline $\begin{array}{l}\text { Cultured } \\
\text { tissues }\end{array}$ & $\begin{array}{l}\text { Biochemical changes; } \\
\text { p-Tau; amyloidosis; } \\
\text { neuron degeneration }\end{array}$ & $\begin{array}{l}\text { Show the AD mechanism at } \\
\text { molecular and cellular level; } \\
\text { controllable environment }\end{array}$ & $\begin{array}{l}\text { No neurological changes; } \\
\text { no plaques; no NFTs }\end{array}$ & (7) \\
\hline Brain slices & Refer to the above & $\begin{array}{l}\text { Show pathology biochemically } \\
\text { and histologically; natural } \\
\text { physiological environment }\end{array}$ & Refer to the above & (99) \\
\hline \multicolumn{5}{|l|}{ Cell models } \\
\hline iPSC & $\begin{array}{l}\text { Biochemical changes; } \\
\text { p-Tau; amyloidosis; } \\
\text { neuron degeneration }\end{array}$ & $\begin{array}{l}\text { Similar genetic } \\
\text { background to humans }\end{array}$ & $\begin{array}{l}\text { No pathological and } \\
\text { neurological changes }\end{array}$ & $(104)$ \\
\hline Neuroblastoma cell & $\begin{array}{l}\text { Specific molecular pathway } \\
\text { like APP processing }\end{array}$ & Rapid and direct & Refer to the above & $(106)$ \\
\hline \multicolumn{5}{|c|}{ Molecular simulation model } \\
\hline $\begin{array}{l}\text { Antibubble } \\
\text { biomachinery }\end{array}$ & $\begin{array}{l}\text { Inflammatory reactivation; } \\
\text { neuronal death }\end{array}$ & $\begin{array}{l}\text { Dissect molecular functions of } \\
\text { endogenous regulatory } \\
\text { pathways in AD }\end{array}$ & $\begin{array}{l}\text { No pathological and } \\
\text { neurological changes }\end{array}$ & $(110)$ \\
\hline
\end{tabular}

AD, Alzheimer's disease; iPSC, induced pluripotent stem cell; p-Tau, hyperphosphorylated tau.

of typical senile plaques and NFTs, most of these models do not, however, represent accurate modeling systems for AD. Although cerebral injections of $A \beta$ produced some features of $\mathrm{AD}$, such as cholinergic dysfunction and behavioral deficits, the progressive neurodegeneration characteristic of AD was not observed. Thus, therapies designed to halt the pathological progression of $\mathrm{AD}$ should not be tested on these models.

\section{In vitro models of $\mathrm{AD}$}

In contrast to in vivo animal models, in vitro models of $\mathrm{AD}$ provide a prompt and direct manner with which to reveal the pathological changes occurring in AD and also to study the responses of nerve cells to treatments at molecular and cellular levels. With the technological advances in cell biology, in vitro AD models have been extensively developed.

Tissue models. Brain tissue, cultured in vitro, provides a good platform for studying the impact of AD-associated substances, such as $A \beta$ on nerve cells (Table III). In an earlier study, Yankner et al (7) treated cultured hippocampal neurons with various synthetic $A \beta$ fragments, and found that $A \beta$ peptides were neurotrophic to undifferentiated neurons, but neurotoxic to mature neurons, wherein the proportion of $A \beta 25-35$ mediated the trophic and toxic effects of $A \beta s$. They also showed that the effects of $A \beta$ can be mimicked by tachykinin antagonists and be completely reversed by specific tachykinin agonists. Similar findings were obtained in the study by Itokazu et al (8). In other studies, in vitro cultured neurons were employed as a model to reproduce the pathophysiological changes involved in $\mathrm{AD}$, including inflammatory reactions, enzyme kinetics, cellular ion homeostasis, altered signal pathways, as well as epigenetic regulations $(94,95)$. Due to the ease of manipulation and the controllable environments, these models are also used to test therapeutics targeted at AD pathophysiology (96) and to reveal the underlying molecular mechanisms $(97,98)$.

Moreover, investigators have developed metabolically competent brain slices in order to model the regulation of AD pathophysiology (Table III). In a previous study, Gong et al (99) treated the metabolically active rat brain slices with okadaic acid to inhibit protein phosphatase $2 \mathrm{~A}$, and found that the hyperphosphorylation of tau at many sites was observed in $\mathrm{AD}$, as well as the accumulation of hyperphosphorylated tau in pyramidal neurons located in the hippocampus and cortex. The phosphorylation of MAP protein was also displayed with this model (99). Thus, this model not only recapitulates the pathological alterations associated with AD biochemically, but also reveals their regional distribution histologically $(99,100)$. In another study, Li et al (101) demonstrated that memantine inhibited and reversed the Alzheimer type abnormal tau hyperphosphorylation and associated neurodegeneration using the metabolically active rat brain slices. Taken together, the findings of these studies demonstrate that brain slices may be used to model $\mathrm{AD}$ at a biochemical level and test potential therapies. Furthermore, neurons in the brain slices, unlike cultured cells, reside in the physiological environment of the brain, consisting of natural extracellular matrix, neuronal connectivity, and neuronal-glial interactions, which points to a more accurate model of $\mathrm{AD}(99)$.

Cell models. Progress in stem cell techniques has broadened our horizon for in vitro disease modeling (Table III). For AD, disease-specific induced pluripotent stem cell (iPSC) lines have been generated from patients with sAD or fAD (102), providing 
an effective approach for disease modeling and drug discovery. In the study by Yagi et al (103), iPSCs were acquired from patients with fAD with mutations in PS1 and PS2, which demonstrated increased levels of $A \beta 42$ in all iPSC lines, supporting the role of $\mathrm{A} \beta$ as an initiating factor in $\mathrm{AD}$ pathogenesis. Using the same method, Israel et al (104) generated iPSCs not only from patients with $\mathrm{fAD}$, but also sporadic cases. In their study, the iPSC-derived neurons exhibited significantly higher levels of A $\beta 40$, phospho-tau, GSK-3 $\beta$, and endosomes (104). Phenotypic analysis revealed that neurons with the genome of sAD cases exhibited the phenotypes observed in fAD samples, suggesting that genetics plays an important, albeit complex, role in sAD. In a previous study, when docosahexaenoic acid (DHA) was used to treat AD iPSC-derived neurons (105), intracellular A $\beta$ loads were notably reduced in SAD and fAD AD neurons, while the stress response of neurons was alleviated in only one patient with SAD, suggesting that heterogeneity exists between patients with SAD and FAD, and indicating that DHA may be effective in some patients with AD. These results indicate that iPSCs provide a unique platform for observing $\mathrm{AD}$-associated phenotypes and therapeutic screening. As iPSC lines from patients with SAD carry different genetic variants, the generation of sufficient stem cells is required to fully guide drug development and enhance our understanding of AD.

Human neuroblastoma cell lines are also used as a model to simulate AD pathophysiology (Table III). Macias et al (106) reported the modeling of the APP-processing pathway in human neuroblastoma cells, which expressed critical components of the amyloidogenic cascade as observed in AD. In a previous study, when carnosic acid (CA) was used to treat human neuroblastoma cells exposed to $\mathrm{A} \beta 42$, it was found that $\mathrm{CA}$ attenuated cell apoptosis by suppressing the activated caspase cascades due to intracellular A $\beta$ aggregation (107). Likewise, the dual blockade of A1 and A2A adenosine receptors has also been demonstrated to prevent $\mathrm{A} \beta$ toxicity in neuroblastoma cells exposed to aluminum chloride (108). These results indicate that human neuroblastoma cell lines can be modified to model certain aspects of AD pathophysiology so as to explore the underlying mechanisms and to develop potential treatment drugs.

Molecular simulation models. Recently, researchers have attempted to simulate the molecular events in the pathophysiology of AD in vitro, so as to establish efficient model systems for speeding up the drug development process (Table III). Denis (109) created an NADPH oxidase-nitric oxide system as an antibubble biomachinery, to imitate the inflammatory cascade seen in AD. This biomachinery induced neuronal death by triggering a guanylyl-cyclase-mediated inflammatory cascade. Researchers have also reported the establishment of molecular dynamics stimulations of model systems that are comprised of an $\mathrm{A} \beta 40$ peptide in water in interaction with $\beta$-sheet breakers mimicking the 17-21 region of $A \beta 40$ sequence (110), showing that $\beta$-sheet breakers inhibit $A \beta 40$ aggregation by stabilizing its native structure. These studies have provided us with streamlined approaches to dissect the molecular functions of endogenous regulatory pathways involved in AD, permitting the direct mechanistic studies of the modulators of these pathways. These approaches are also used to screen possible therapeutic compounds efficiently and evidently.

\section{Current status and future development of experimental models of AD}

Current status of experimental models of $A D$ and strategies for model selection. Experimental models of AD have greatly enhanced our understanding of the disease process of AD and promoted the development of novel therapies. While transgenic animal models enable researchers to explore the genetic etiology of $\mathrm{AD}$, and have led to the establishment of more complete models of AD which may be used for genetic manipulation and the identification of novel therapies, non-transgenic animal models recapitulate the natural process of AD including its occurrence, evolution and prognosis, which has shown a high application value in earlier studies. By contrast, in vitro models isolate specific molecular pathways from others in $\mathrm{AD}$, permitting therapeutic screening in a rapid and direct way. Among them, transgenic models are the most popularly used in AD research.

However, there are obvious limitations with current experimental models of AD. To date, none of the existing models reproduce all aspects of human $\mathrm{AD}$. Although transgenic animals for modeling $\mathrm{AD}$ produce $\mathrm{A} \beta$ plaques and NFTs with a spatial and temporal distribution similar to humans, most of these models mimic fAD closely but not SAD conditions, and the latter accounts for $>90 \%$ of AD cases (111). There are certain pathophysiological differences between fAD and SAD, in which one is driven primarily by $\mathrm{A} \beta$ overproduction and the other is not. This may explain why so many treatments have shown significant benefits by suppressing the $\beta$-secretase in animal models carrying $\mathrm{hAPP}_{\text {Swe }}$ genes, yet fail to clinically treat SAD. Human iPSCs isolated from patients with AD may serve as a valuable tool to bridge the gap between animal studies and clinical testing. However, sAD is characterized by its multifactorial nature and various clinical phenotypes, which may differ further during the long period of pathology development; this may lead to inconsistencies in different iPSC lines even from the same patient. In addition, there are marked differences in the genetic background, biochemical composition and metabolism among different animals that make it difficult to compare the resulting data across species. Due to the complexity of AD conditions, further studies are warranted to define the pathological signatures of different forms of AD in humans and in model animals.

The selection of one particular model for AD research should be based on the research objectives and the advantages of each model. In general, transgenic animals are of the first choice for modeling AD pathophysiology and testing new therapeutics, although new treatments should be tested in natural models, such as primates prior to clinical trials. In vitro models provide a fast and efficient means of exploring the molecular mechanisms behind AD and to preliminarily screen new therapeutics. Each type of AD model mimics specific stages of AD pathophysiological changes (Fig. 2A) and shows different efficiency in therapeutic screening (Fig. 2B), which should be taken into account in AD model selection.

The future of experimental models of $A D$. The advent of interference RNAs and antibody arrays may make it possible to acquire 'perfect' models in the years to come by using these substances through epigenetic mechanisms. It is expected 

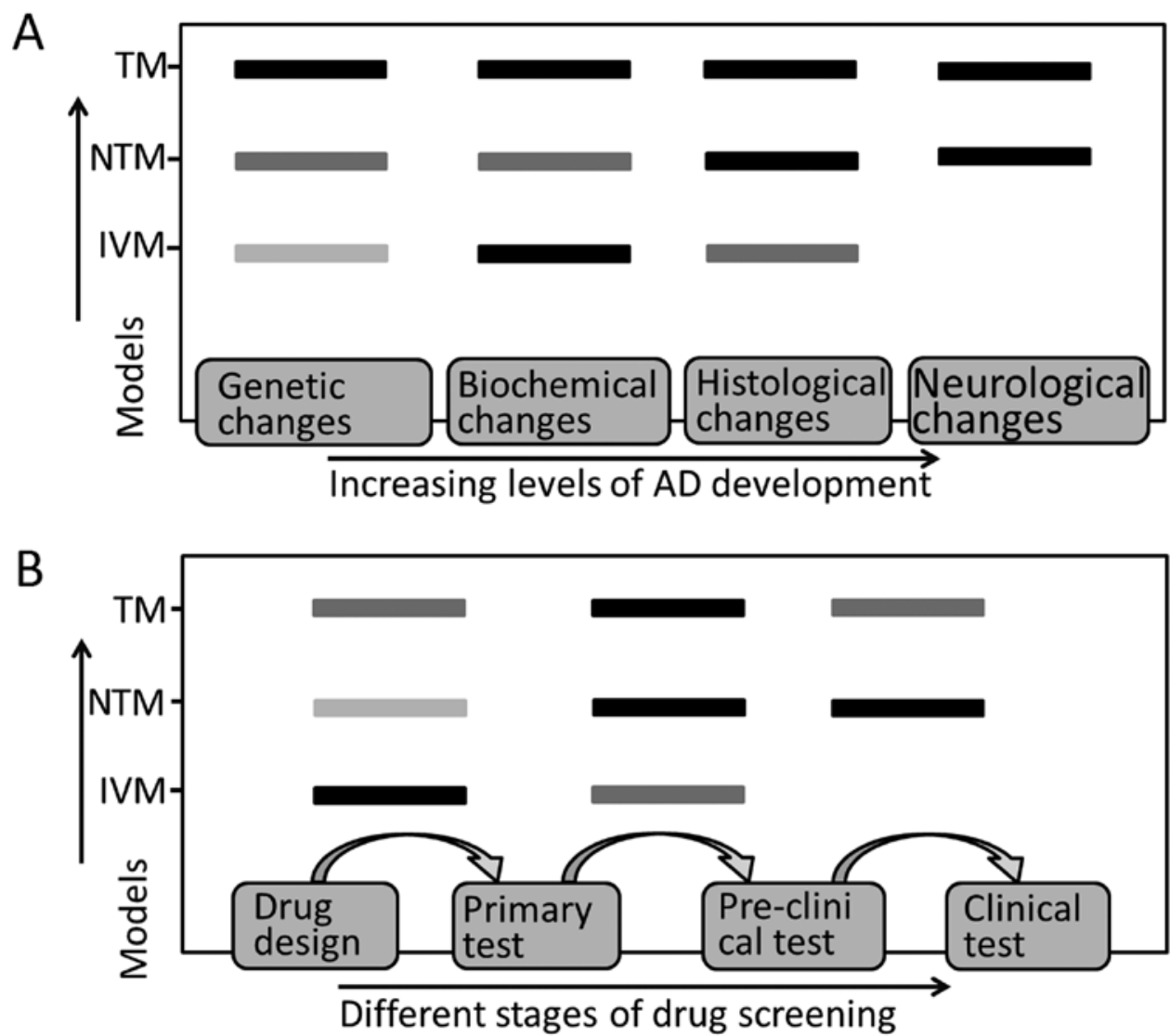

Figure 2. Schematic map illustrating (A) the different stages of AD development and (B) the different stages of drug screening that each type of model covers. The gray value of each bar represents the efficiency of the corresponding AD model. Black boxes represent the highest value for AD research, dark grey boxes represent moderate value and light grey boxes represent the poorest value. This may provide guidance for choosing between transgenic, non-transgenic and in vitro models in $\mathrm{AD}$ research. IVM, in vitro model; NTM, non-transgenic model; TM, transgenic model; AD, Alzheimer's disease.

that there will be a wider application of genetic technology to models of AD (111). Furthermore, the development of optogenetics provides an appealing method with which to evaluate the physiological changes of model cells at a cellular level with a level of high accuracy (94). The use of this technique in $\mathrm{AD}$ will allow the observation of the 'behavioral responses' of cell models or tissue models; however, there are limited studies on this aspect to date (94) and further investigations into this matter are thus required. In addition, computational technology combined with the molecular simulation model may be used to mimi molecular structures, such as $\mathrm{A} \beta$ peptide, and screen novel therapeutics efficiently $(110,112)$. It is likely that in the coming years, these techniques will be widely used in the research of AD.

Recently, attention has been focused on combined approaches that rely on the limited existing models in order to induce a pronounced pathology. The models of one type may not accurately reproduce the anatomical distribution of lesions observed in humans, although biochemically, they are quite similar to human conditions. In terms of neurological impairments, neuroanatomy and endocrine systems, animals models are superior to in vitro models. By contrast, in vitro models exhibit significant advantages over animal models in dissecting signaling pathways, performing modifier screenings and analyzing families of mutations. Using a combination of multiple models has been shown to accelerate the pathogenic disclosure and drug development process in $\mathrm{AD}$ (113). This may be one direction for modeling $\mathrm{AD}$ in future studies.

\section{Conclusion}

Over the past decades, great progress has been made in the understanding of the athophysiology of $\mathrm{AD}$ and the underlying genetic and biochemical alterations. In parallel, a variety of experimental models of $\mathrm{AD}$, including animal models and in vitro models, have been developed. Animal models cast light on the neurodegeneration conditions and facilitate the exploration of pathological, physiological, and behavioral changes occurring in AD. In vitro models allow accurate and reproducible control of extracellular environments, providing additional information for animal models. All these models are particularly suitable for studying the pathophysiology of $\mathrm{AD}$ and evaluating potential therapies. Each model offers particular benefits, as well as specific limitations. Selecting an experimental model is dependent on both the research goals and the underlying objectives of the study.

As a whole, the experimental models of AD discussed in this review have contributed to our understanding of $\mathrm{AD}$. Nevertheless, none of these models are able to reproduce all aspects of disease progression in the vast majority of $\mathrm{AD}$ subtypes. Thus, current models require additional modifica- 
tions so as to fully replicate the complex conditions of human AD. Undoubtedly, experimental models will continue to play a vital role in future AD research.

\section{Acknowledgements}

This study was supported by the National High Technology Research and Development Program ('973' program, no. 2014CB541603; '863' program, no. 2013AA020106) and the National Natural Science Foundation (nos. 81301061 and 81200916) of China.

\section{References}

1. Li XY, Bao XJ and Wang RZ: Potential of neural stem cell-based therapies for Alzheimer's disease. J Neurosci Res 93: 1313-1324, 2015.

2. Bateman RJ, Xiong C, Benzinger TL, Fagan AM, Goate A, Fox NC, Marcus DS, Cairns NJ, Xie X, Blazey TM, et al; Dominantly Inherited Alzheimer Network: Clinical and biomarker changes in dominantly inherited Alzheimer's disease. N Engl J Med 367: 795-804, 2012.

3. Fleisher AS, Chen K, Quiroz YT, Jakimovich LJ, Gomez MG, Langois CM, Langbaum JB, Ayutyanont N, Roontiva A, Thiyyagura $\mathrm{P}$, et al: Florbetapir PET analysis of amyloid- $\beta$ deposition in the presenilin 1 E280A autosomal dominant Alzheimer's disease kindred: a cross-sectional study. Lancet Neurol 11: 1057-1065, 2012.

4. Do Carmo S and Cuello AC: Modeling Alzheimer's disease in transgenic rats. Mol Neurodegener 8: 37, 2013.

5. Elder GA, Gama Sosa MA and De Gasperi R: Transgenic mouse models of Alzheimer's disease. Mt Sinai J Med 77: 69-81, 2010.

6. Mattsson MO and Simkó M: Is there a relation between extremely low frequency magnetic field exposure, inflammation and neurodegenerative diseases? A review of in vivo and in vitro experimental evidence. Toxicology 301: 1-12, 2012.

7. Yankner BA, Duffy LK and Kirschner DA: Neurotrophic and neurotoxic effects of amyloid beta protein: reversal by tachykinin neuropeptides. Science 250: 279-282, 1990

8. Itokazu Y, Kato-Negishi M, Nakatani Y, Ariga T and Yu RK: Effects of amyloid $\beta$-peptides and gangliosides on mouse neural stem cells. Neurochem Res 38: 2019-2027, 2013.

9. Blasko I, Stampfer-Kountchev M, Robatscher P, Veerhuis R, Eikelenboom P and Grubeck-Loebenstein B: How chronic inflammation can affect the brain and support the development of Alzheimer's disease in old age: the role of microglia and astrocytes. Aging Cell 3: 169-176, 2004.

10. Schindowski K, Bretteville A, Leroy K, Bégard S, Brion JP, Hamdane $M$ and Buée L: Alzheimer's disease-like tau neuropathology leads to memory deficits and loss of functional synapses in a novel mutated tau transgenic mouse without any motor deficits. Am J Pathol 169: 599-616, 2006.

11. Terry RD, Masliah E, Salmon DP, Butters N, DeTeresa R, Hill R, Hansen LA and Katzman R: Physical basis of cognitive alterations in Alzheimer's disease: synapse loss is the major correlate of cognitive impairment. Ann Neurol 30: 572-580, 1991.

12. Inestrosa NC, Alvarez A, Pérez CA, Moreno RD, Vicente M, Linker C, Casanueva OI, Soto C and Garrido J: Acetylcholinesterase accelerates assembly of amyloid-betapeptides into Alzheimer's fibrils: possible role of the peripheral site of the enzyme. Neuron 16: 881-891, 1996.

13. Alvarez A, Opazo C, Alarcón R, Garrido J and Inestrosa NC: Acetylcholinesterase promotes the aggregation of amyloid-betapeptide fragments by forming a complex with the growing fibrils. J Mol Biol 272: 348-361, 1997.

14. Alvarez A, Alarcón R, Opazo C, Campos EO, Muñoz FJ, Calderón FH, Dajas F, Gentry MK, Doctor BP, De Mello FG and Inestrosa NC: Stable complexes involving acetylcholinesterase and amyloid-beta peptide change the biochemical properties of the enzyme and increase the neurotoxicity of Alzheimer's fibrils. J Neurosci 18: 3213-3223, 1998.

15. Yamada K and Nabeshima T: Animal models of Alzheimer's disease and evaluation of anti-dementia drugs. Pharmacol Ther 88: 93-113, 2000.
16. Chartier-Harlin MC, Crawford F, Houlden H, Warren A, Hughes D, Fidani L, Goate A, Rossor M, Roques P, Hardy J and Mullan M: Early-onset Alzheimer's disease caused by mutations at codon 717 of the beta-amyloid precursor protein gene. Nature 353: 844-846, 1991.

17. Rogaev EI, Sherrington R, Rogaeva EA, Levesque G, Ikeda M, Liang Y, Chi H, Lin C, Holman K, Tsuda T, et al: Familial Alzheimer's disease in kindreds with missense mutations in a gene on chromosome 1 related to the Alzheimer's disease type 3 gene. Nature 376: 775-778, 1995.

18. Levy-Lahad E, Wijsman EM, Nemens E, Anderson L, Goddard KA, Weber JL, Bird TD and Schellenberg GD: A familial Alzheimer's disease locus on chromosome 1. Science 269: 970-973, 1995.

19. Goedert M and Spillantini MG: Tau mutations in frontotemporal dementia FTDP-17 and their relevance for Alzheimer's disease. Biochim Biophys Acta 1502: 110-121, 2000.

20. Levy-Lahad E, Lahad A, Wijsman EM, Bird TD and Schellenberg GD: Apolipoprotein E genotypes and age of onset in early-onset familial Alzheimer's disease. Ann Neurol 38: 678-680, 1995.

21. Neha, Sodhi RK, Jaggi AS and Singh N: Animal models of dementia and cognitive dysfunction. Life Sci 109: 73-86, 2014.

22. Liao A, Nitsch RM, Greenberg SM, Finckh U, Blacker D, Albert M, Rebeck GW, Gomez-Isla T, Clatworthy A, Binetti G, et al: Genetic association of an alpha2-macroglobulin (Val1000lle) polymorphism and Alzheimer's disease. Hum Mol Genet 7: 1953-1956, 1998.

23. Dahiyat M, Cumming A, Harrington C, Wischik C, Xuereb J, Corrigan F, Breen G, Shaw D and St Clair D: Association between Alzheimer's disease and the NOS3 gene. Ann Neurol 46: 664-667, 1999.

24. Lithner CU, Hedberg MM and Nordberg A: Transgenic mice as a model for Alzheimer's disease. Curr Alzheimer Res 8: 818-831, 2011.

25. Quon D, Wang Y, Catalano R, Scardina JM, Murakami K and Cordell B: Formation of beta-amyloid protein deposits in brains of transgenic mice. Nature 352: 239-241, 1991.

26. Higgins LS, Rodems JM, Catalano R, Quon D and Cordell B: Early Alzheimer disease-like histopathology increases in frequency with age in mice transgenic for beta-APP751. Proc Natl Acad Sci USA 92: 4402-4406, 1995.

27. Games D, Adams D, Alessandrini R, Barbour R, Berthelette P, Blackwell C, Carr T, Clemens J, Donaldson T, Gillespie F, et al: Alzheimer-type neuropathology in transgenic mice overexpressing V717F beta-amyloid precursor protein. Nature 373: 523-527, 1995.

28. Hsiao K, Chapman P, Nilsen S, Eckman C, Harigaya Y, Younkin S, Yang F and Cole G: Correlative memory deficits, Abeta elevation, and amyloid plaques in transgenic mice. Science 274: 99-102, 1996.

29. Calhoun ME, Wiederhold KH, Abramowski D, Phinney AL, Probst A, Sturchler-Pierrat C, Staufenbiel M, Sommer B and Jucker M: Neuron loss in APP transgenic mice. Nature 395: 755-756, 1998.

30. Richards JG, Higgins GA, Ouagazzal AM, Ozmen L, Kew JN, Bohrmann B, Malherbe P, Brockhaus M, Loetscher H, Czech C, et al: PS2APP transgenic mice, coexpressing hPS2mut and hAPPswe, show age-related cognitive deficits associated with discrete brain amyloid deposition and inflammation. J Neurosci 23: 8989-9003, 2003.

31. Braidy N, Muñoz P, Palacios AG, Castellano-Gonzalez G, Inestrosa NC, Chung RS, Sachdev P and Guillemin GJ: Recent rodent models for Alzheimer's disease: clinical implications and basic research. J Neural Transm 119: 173-195, 2012.

32. Lewis J, Dickson DW, Lin WL, Chisholm L, Corral A, Jones G, Yen SH, Sahara N, Skipper L, Yager D, et al: Enhanced neurofibrillary degeneration in transgenic mice expressing mutant tau and APP. Science 293: 1487-1491, 2001.

33. Götz J, Probst A, Spillantini MG, Schäfer T, Jakes R, Bürki K and Goedert M: Somatodendritic localization and hyperphosphorylation of tau protein in transgenic mice expressing the longest human brain tau isoform. EMBO J 14: 1304-1313, 1995.

34. James ND, Davis DR, Sindon J, Hanger DP, Brion JP, Miller CC, Rosenberg MP, Anderton BH and Propst F: Neurodegenerative changes including altered tau phosphorylation and neurofilament immunoreactivity in mice transgenic for the serine/threonine kinase Mos. Neurobiol Aging 17: 235-241, 1996. 
35. Allen B, Ingram E, Takao M, Smith MJ, Jakes R, Virdee K, Yoshida H, Holzer M, Craxton M, Emson PC, et al: Abundant tau filaments and nonapoptotic neurodegeneration in transgenic mice expressing human P301S tau protein. J Neurosci 22: 9340-9351, 2002.

36. Forman MS, Lal D, Zhang B, Dabir DV, Swanson E, Lee VM and Trojanowski JQ: Transgenic mouse model of tau pathology in astrocytes leading to nervous system degeneration. J Neurosci 25: 3539-3550, 2005.

37. Higuchi M, Zhang B, Forman MS, Yoshiyama Y, Trojanowski JQ and Lee VM: Axonal degeneration induced by targeted expression of mutant human tau in oligodendrocytes of transgenic mice that model glial tauopathies. J Neurosci 25: 9434-9443, 2005.

38. Ribé EM, Pérez M, Puig B, Gich I, Lim F, Cuadrado M, Sesma T, Catena S, Sánchez B, Nieto M, et al: Accelerated amyloid deposition, neurofibrillary degeneration and neuronal loss in double mutant APP/tau transgenic mice. Neurobiol Dis 20: 814-822, 2005.

39. Götz J, Chen F, van Dorpe J and Nitsch RM: Formation of neurofibrillary tangles in P3011 tau transgenic mice induced by Abeta 42 fibrils. Science 293: 1491-1495, 2001.

40. Oddo S, Caccamo A, Shepherd JD, Murphy MP, Golde TE, Kayed R, Metherate R, Mattson MP, Akbari Y and LaFerla FM: Triple-transgenic model of Alzheimer's disease with plaques and tangles: Intracellular Abeta and synaptic dysfunction. Neuron 39: 409-421, 2003

41. Janelsins MC, Mastrangelo MA, Oddo S, LaFerla FM, Federoff HJ and Bowers WJ: Early correlation of microglial activation with enhanced tumor necrosis factor-alpha and monocyte chemoattractant protein-1 expression specifically within the entorhinal cortex of triple transgenic Alzheimer's disease mice. J Neuroinflammation 2: 23, 2005.

42. Kimura R and Ohno M: Impairments in remote memory stabilization precede hippocampal synaptic and cognitive failures in 5XFAD Alzheimer mouse model. Neurobiol Dis 33: 229-235, 2009.

43. Oakley H, Cole SL, Logan S, Maus E, Shao P, Craft J, GuillozetBongaarts A, Ohno M, Disterhoft J, Van Eldik L, et al: Intraneuronal beta-amyloid aggregates, neurodegeneration, and neuron loss in transgenic mice with five familial Alzheimer's disease mutations: Potential factors in amyloid plaque formation. J Neurosci 26: 10129-10140, 2006.

44. Clarke J, Thornell A, Corbett D, Soininen H, Hiltunen M and Jolkkonen J: Overexpression of APP provides neuroprotection in the absence of functional benefit following middle cerebral artery occlusion in rats. Eur J Neurosci 26: 1845-1852, 2007.

45. Flood DG, Lin YG, Lang DM, Trusko SP, Hirsch JD, Savage MJ, Scott RW and Howland DS: A transgenic rat model of Alzheimer's disease with extracellular Abeta deposition. Neurobiol Aging 30: 1078-1090, 2009.

46. Ruiz-Opazo N, Kosik KS, Lopez LV, Bagamasbad P, Ponce LR and Herrera VL: Attenuated hippocampus-dependent learning and memory decline in transgenic TgAPPswe Fischer-344 rats. Mol Med 10: 36-44, 2004.

47. Filipcik P, Zilka N, Bugos O, Kucerak J, Koson P, Novak P and Novak M: First transgenic rat model developing progressive cortical neurofibrillary tangles. Neurobiol Aging 33: 1448-1456, 2012.

48. Van Dam D and De Deyn PP: Animal models in the drug discovery pipeline for Alzheimer's disease. Br J Pharmacol 164 $1285-1300,2011$

49. Iwata N, Tsubuki S, Takaki Y, Watanabe K, Sekiguchi M, Hosoki E, Kawashima-Morishima M, Lee HJ, Hama E, Sekine-Aizawa Y and Saido TC: Identification of the major Abeta1-42-degrading catabolic pathway in brain parenchyma: suppression leads to biochemical and pathological deposition. Nat Med 6: 143-150, 2000.

50. Vekrellis K, Ye Z, Qiu WQ, Walsh D, Hartley D, Chesneau V, Rosner MR and Selkoe DJ: Neurons regulate extracellular levels of amyloid beta-protein via proteolysis by insulin-degrading enzyme. J Neurosci 20: 1657-1665, 2000

51. Solà C, García-Ladona FJ, Sarasa M, Mengod G, Probst A, Palacios G and Palacios JM: Beta APP gene expression is increased in the rat brain after motor neuron axotomy. Eur $\mathrm{J}$ Neurosci 5: 795-808, 1993.

52. Gonzalo-Ruiz A, González I and Sanz-Anquela JM: Effects of beta-amyloid protein on serotoninergic, noradrenergic, and cholinergic markers in neurons of the pontomesencephalic tegmentum in the rat. J Chem Neuroanat 26: 153-169, 2003.
53. Du P, Wood KM, Rosner MH, Cunningham D, Tate B and Geoghegan KF: Dominance of amyloid precursor protein sequence over host cell secretases in determining beta-amyloid profiles studies of interspecies variation and drug action by internally standardized immunoprecipitation/mass spectrometry. J Pharmacol Exp Ther 320: 1144-1152, 2007.

54. Beck M, Bigl V and Rossner S: Guinea pigs as a nontransgenic model for APP processing in vitro and in vivo. Neurochem Res 28: 637-644, 2003.

55. Chen Y, Wei G, Nie H, Lin Y, Tian H, Liu Y, Yu X, Cheng S, Yan $\mathrm{R}$, Wang $\mathrm{Q}$, et al: $\beta$-Asarone prevents autophagy and synaptic loss by reducing ROCK expression in asenescence-accelerated prone 8 mice. Brain Res 1552: 41-54, 2014.

56. Takeda T, Hosokawa M, Takeshita S, Irino M, Higuchi K, Matsushita T, Tomita Y, Yasuhira K, Hamamoto H and Shimizu K: A new murine model of accelerated senescence. Mech Ageing Dev 17: 183-194, 1981.

57. Flood JF and Morley JE: Learning and memory in the SAMP8 mouse. Neurosci Biobehav Rev 22: 1-20, 1998.

58. Stefanova NA, Kozhevnikova OS, Vitovtov AO, Maksimova KY, Logvinov SV, Rudnitskaya EA, Korbolina EE, Muraleva NA and Kolosova NG: Senescence-accelerated OXYS rats: a model of age-related cognitive decline with relevance to abnormalities in Alzheimer disease. Cell Cycle 13: 898-909, 2014

59. Stefanova NA, Muraleva NA, Skulachev VP and Kolosova NG: Alzheimer's disease-like pathology in senescence-accelerated OXYS rats can be partially retarded with mitochondria-targeted antioxidant SkQ1. J Alzheimers Dis 38: 681-694, 2014.

60. Poon HF, Calabrese V, Scapagnini G and Butterfield DA: Free radicals: key to brain aging and heme oxygenase as a cellular response to oxidative stress. J Gerontol A Biol Sci Med Sci 59: 478-493, 2004.

61. Bosch MN, Pugliese M, Gimeno-Bayón J, Rodríguez MJ and Mahy N: Dogs with cognitive dysfunction syndrome: A natural model of Alzheimer's disease. Curr Alzheimer Res 9: 298-314, 2012.

62. Head E, Callahan H, Muggenburg BA, Cotman CW and Milgram NW: Visual-discrimination learning ability and beta-amyloid accumulation in the dog. Neurobiol Aging 19: 415-425, 1998.

63. Head E, McCleary R, Hahn FF, Milgram NW and Cotman CW: Region-specific age at onset of beta-amyloid in dogs. Neurobiol Aging 21: 89-96, 2000.

64. Hou Y, White RG, Bobik M, Marks JS and Russell MJ: Distribution of beta-amyloid in the canine brain. Neuroreport 8: 1009-1012, 1997.

65. Satou T, Cummings BJ, Head E, Nielson KA, Hahn FF, Milgram NW, Velazquez P, Cribbs DH, Tenner AJ and Cotman CW: The progression of beta-amyloid deposition in the frontal cortex of the aged canine. Brain Res 774: 35-43, 1997.

66. Cuyckens F, Balcaen LI, De Wolf K, De Samber B, Van Looveren C, Hurkmans R and Vanhaecke F: Use of the bromine isotope ratio in HPLC-ICP-MS and HPLC-ESI-MS analysis of a new drug in development. Anal Bioanal Chem 390: 1717-1729, 2008.

67. Head E: Combining an antioxidant-fortified diet with behavioral enrichment leads to cognitive improvement and reduced brain pathology in aging canines: strategies for healthy aging. Ann NY Acad Sci 1114: 398-406, 2007.

68. Papaioannou N, Tooten PC, van Ederen AM, Bohl JR, Rofina J, Tsangaris $\mathrm{T}$ and Gruys E: Immunohistochemical investigation of the brain of aged dogs. I. Detection of neurofibrillary tangles and of 4-hydroxynonenal protein, an oxidative damage product, in senile plaques. Amyloid 8: 11-21, 2001.

69. Pugliese M, Mascort J, Mahy N and Ferrer I: Diffuse beta-amyloid plaques and hyperphosphorylated tau are unrelated processes in aged dogs with behavioral deficits. Acta Neuropathol 112: 175-183, 2006 .

70. Languille S, Blanc S, Blin O, Canale CI, Dal-Pan A, Devau G, Dhenain M, Dorieux O, Epelbaum J, Gomez D, et al: The grey mouse lemur: a non-human primate model for ageing studies. Ageing Res Rev 11: 150-162, 2012

71. Bons N, Rieger F, Prudhomme D, Fisher A and Krause KH: Microcebus murinus: a useful primate model for human cerebral aging and Alzheimer's disease? Genes Brain Behav 5: 120-130, 2006.

72. Kraska A, Dorieux O, Picq JL, Petit F, Bourrin E, Chenu E, Volk A, Perret M, Hantraye P, Mestre-Frances N, et al: Age-associated cerebral atrophy in mouse lemur primates. Neurobiol Aging 32: 894-906, 2011. 
73. Giannakopoulos P, Silhol S, Jallageas V, Mallet J, Bons N, Bouras C and Delaère P: Quantitative analysis of tau proteinimmunoreactive accumulations and beta amyloid protein deposits in the cerebral cortex of the mouse lemur, Microcebus murinus. Acta Neuropathol 94: 131-139, 1997.

74. Laurijssens B, Aujard F and Rahman A: Animal models of Alzheimer's disease and drug development. Drug Discov Today Technol 10: e319-e327, 2013.

75. Bélanger N, Grégoire L, Bédard PJ and Di Paolo T: DHEA improves symptomatic treatment of moderately and severely impaired MPTP monkeys. Neurobiol Aging 27: 1684-1693, 2006.

76. Yue F, Lu C, Ai Y, Chan P and Zhang Z: Age-associated changes of cerebrospinal fluid amyloid- $\beta$ and tau in cynomolgus monkeys. Neurobiol Aging 35: 1656-1659, 2014.

77. Molteni R, Barnard RJ, Ying Z, Roberts CK and Gómez-Pinilla F: A high-fat, refined sugar diet reduces hippocampal brain-derived neurotrophic factor, neuronal plasticity, and learning. Neuroscience 112: 803-814, 2002.

78. Demetrius LA and Driver J: Alzheimer's as a metabolic disease. Biogerontology 14: 641-649, 2013.

79. Herculano B, Tamura M, Ohba A, Shimatani M, Kutsuna N and Hisatsune T: $\beta$-alanyl-L-histidine rescues cognitive deficits caused by feeding a high fat diet in a transgenic mouse model of Alzheimer's disease. J Alzheimers Dis 33: 983-997, 2013.

80. Haley RW and Dietschy JM: Is there a connection between the concentration of cholesterol circulating in plasma and the rate of neuritic plaque formation in Alzheimer disease? Arch Neurol 57: 1410-1412, 2000

81. Gibson Wood W,Eckert GP, Igbavboa U and Müller WE: Amyloid beta-protein interactions with membranes and cholesterol: Causes or casualties of Alzheimer's disease. Biochim Biophys Acta 1610: 281-290, 2003

82. Wu YY, Wang X, Tan L, Liu D, Liu XH, Wang Q, Wang JZ and Zhu LQ: Lithium attenuates scopolamine-induced memory deficits with inhibition of GSK-3 $\beta$ and preservation of postsynaptic components. J Alzheimers Dis 37: 515-527, 2013.

83. Vandal M, White PJ, Tremblay C, St-Amour I, Chevrier G, Emond V, Lefrançois D, Virgili J, Planel E, Giguere Y, et al: Insulin reverses the high-fat diet-induced increase in brain $A \beta$ and improves memory in an animal model of Alzheimer disease. Diabetes 63: 4291-4301, 2014.

84. Pinton S, Brüning CA, Sartori Oliveira CE, Prigol $M$ and Nogueira CW: Therapeutic effect of organoselenium dietary supplementation in a sporadic dementia of Alzheimer's type model in rats. J Nutr Biochem 24: 311-317, 2013

85. Nakamura S, Murayama N, Noshita T, Annoura H and Ohno T: Progressive brain dysfunction following intracerebroventricular infusion of beta(1-42)-amyloid peptide. Brain Res 912: 128-136, 2001.

86. Winslow JT and Camacho F: Cholinergic modulation of a decrement in social investigation following repeated contacts between mice. Psychopharmacology (Berl) 121: 164-172, 1995

87. Sain H, Sharma B, Jaggi AS and Singh N: Pharmacological investigations on potential of peroxisome proliferator-activated receptor-gamma agonists in hyperhomocysteinemia-induced vascular dementia in rats. Neuroscience 192: 322-333, 2011.

88. Kamat PK, Rai S and Nath C: Okadaic acid induced neurotoxicity: An emerging tool to study Alzheimer's disease pathology. Neurotoxicology 37: 163-172, 2013.

89. Zhang J, Li P, Wang Y, Liu J, Zhang Z, Cheng W and Wang Y Ameliorative effects of a combination of baicalin, jasminoidin and cholic acid on ibotenic acid-induced dementia model in rats PLoS One 8: e56658, 2013.

90. Bonda DJ, Lee HG, Blair JA, Zhu X, Perry G and Smith MA: Role of metal dyshomeostasis in Alzheimer's disease. Metallomics 3 . 267-270, 2011.

91. Squire LR and Zola-Morgan S: Memory: Brain systems and behavior. Trends Neurosci 11: 170-175, 1988 .

92. Liu J, Zhang Z, Li JT, Zhu YH, Zhou HL, Liu S and Wang TH: Effects of NT-4 gene modified fibroblasts transplanted into AD rats. Neurosci Lett 466: 1-5, 2009.

93. Savage LM, Sweet AJ, Castillo R and Langlais PJ: The effects of lesions to thalamic lateral internal medullary lamina and posterior nuclei on learning, memory and habituation in the rat. Behav Brain Res 82: 133-147, 1997.

94. Avaliani N, Sørensen AT, Ledri M, Bengzon J, Koch P, Brüstle O, Deisseroth K, Andersson M and Kokaia M: Optogenetics reveal delayed afferent synaptogenesis on grafted human-induced pluripotent stem cell-derived neural progenitors. Stem Cells 32: 3088-3098, 2014.
95. Green KN, Smith IF and Laferla FM: Role of calcium in the pathogenesis of Alzheimer's disease and transgenic models. Subcell Biochem 45: 507-521, 2007.

96. Nepovimova E, Uliassi E, Korabecny J, Peña-Altamira LE, Samez S, Pesaresi A, Garcia GE, Bartolini M, Andrisano V, Bergamini C, et al: Multitarget drug design strategy: quinone-tacrine hybrids designed to block amyloid- $\beta$ aggregation and to exert anticholinesterase and antioxidant effects. J Med Chem 57: 8576-8589, 2014

97. Akhter R, Sanphui P and Biswas SC: The essential role of p53-up-regulated modulator of apoptosis (Puma) and its regulation by FoxO3a transcription factor in $\beta$-amyloid-induced neuron death. J Biol Chem 289: 10812-10822, 2014.

98. Matlack KE, Tardiff DF, Narayan P, Hamamichi S, Caldwell KA, Caldwell GA and Lindquist S: Clioquinol promotes the degradation of metal-dependent amyloid- $\beta$ (A $\beta$ ) oligomers to restore endocytosis and ameliorate A $\beta$ toxicity. Proc Natl Acad Sci USA 111: 4013-4018, 2014

99. Gong CX, Lidsky T, Wegiel J, Grundke-Iqbal I and Iqbal K: Metabolically active rat brain slices as a model to study the regulation of protein phosphorylation in mammalian brain. Brain Res Brain Res Protoc 6: 134-140, 2001.

100. Roder S, Danober L, Pozza MF, Lingenhoehl K, Wiederhold KH and Olpe HR: Electrophysiological studies on the hippocampus and prefrontal cortex assessing the effects of amyloidosis in amyloid precursor protein 23 transgenic mice. Neuroscience 120: 705-720, 2003

101.Li L, Sengupta A, Haque N, Grundke-Iqbal I and Iqbal K: Memantine inhibits and reverses the Alzheimer type abnormal hyperphosphorylation of tau and associated neurodegeneration. FEBS Lett 566: 261-269, 2004.

102. Jang J, Yoo JE, Lee JA, Lee DR, Kim JY, Huh YJ, Kim DS, Park CY, Hwang DY, Kim HS, et al: Disease-specific induced pluripotent stem cells: A platform for human disease modeling and drug discovery. Exp Mol Med 44: 202-213, 2012.

103. Yagi T, Ito D, Okada Y, Akamatsu W, Nihei Y, Yoshizaki T, Yamanaka S, Okano $\mathrm{H}$ and Suzuki N: Modeling familial Alzheimer's disease with induced pluripotent stem cells. Hum Mol Genet 20: 4530-4539, 2011.

104. Israel MA, Yuan SH, Bardy C, Reyna SM, Mu Y, Herrera C, Hefferan MP, Van Gorp S, Nazor KL, Boscolo FS, et al: Probing sporadic and familial Alzheimer's disease using induced pluripotent stem cells. Nature 482: 216-220, 2012.

105. Kondo T, Asai M, Tsukita K, Kutoku Y, Ohsawa Y, Sunada Y, Imamura K, Egawa N, Yahata N, Okita K, et al: Modeling Alzheimer's disease with iPSCs reveals stress phenotypes associated with intracellular $\mathrm{A} \beta$ and differential drug responsiveness. Cell Stem Cell 12: 487-496, 2013

106. Macias MP, Gonzales AM, Siniard AL, Walker AW, Corneveaux JJ, Huentelman MJ, Sabbagh MN and Decourt B: A cellular model of amyloid precursor protein processing and amyloid- $\beta$ peptide production. J Neurosci Methods 223: 114-122, 2014.

107. Meng P, Yoshida H, Tanji K, Matsumiya T, Xing F, Hayakari R, Wang L, Tsuruga K, Tanaka $\mathrm{H}$, Mimura J, et al: Carnosic acid attenuates apoptosis induced by amyloid- $\beta 1-42$ or $1-43$ in SH-SY5Y human neuroblastoma cells. Neurosci Res 94: 1-9, 2015.

108. Giunta S, Andriolo V and Castorina A: Dual blockade of the $\mathrm{A} 1$ and $\mathrm{A} 2 \mathrm{~A}$ adenosine receptor prevents amyloid beta toxicity in neuroblastoma cells exposed to aluminum chloride. Int J Biochem Cell Biol 54: 122-136, 2014.

109. Denis PA: Alzheimer's disease: A gas model. The NADPH oxidase-Nitric Oxide system as an antibubble biomachinery. Med Hypotheses 81: 976-987, 2013.

110. Minicozzi V, Chiaraluce R, Consalvi V, Giordano C, Narcisi C, Punzi P, Rossi GC and Morante S: Computational and experimental studies on $\beta$-sheet breakers targeting $A \beta 1-40$ fibrils. J Biol Chem 289: 11242-11252, 2014.

111. Götz J and Ittner LM: Animal models of Alzheimer's disease and frontotemporal dementia. Nat Rev Neurosci 9: 532-544, 2008.

112. Viet MH, Chen CY, Hu CK, Chen YR and Li MS: Discovery of dihydrochalcone as potential lead for Alzheimer's disease: In silico and in vitro study. PLoS One 8: e79151, 2013.

113. Lo AC, Iscru E, Blum D, Tesseur I, Callaerts-Vegh Z, Buée L, De Strooper B, Balschun D and D'Hooge R: Amyloid and tau neuropathology differentially affect prefrontal synaptic plasticity and cognitive performance in mouse models of Alzheimer's disease. J Alzheimers Dis 37: 109-125, 2013.

114. Okuma Y and Nomura Y: Senescence-accelerated mouse (SAM) as an animal model of senile dementia: pharmacological, neurochemical and molecular biological approach. Jpn J Pharmacol 78: 399-404, 1998. 